\title{
Dienogest versus gonadotropin-releasing hormone analogue for the clinical treatment of endometriosis: a systematic review and meta-analysis
}

\author{
Sofia Andrade de Oliveira ${ }^{1 *}$, Bárbara Souza Melo², Marina Fernandes Pereira ${ }^{3}$
}

\author{
${ }^{1}$ Department of Medicine, Bahia State University, Salvador, Brazil \\ ${ }^{2}$ Department of Medicine, Santo Antonio Hospital, Salvador, Brazil \\ ${ }^{3}$ Department of Medicine, Santa Isabel Hospital, Salvador, Brazil
}

Received: 03 July 2017

Revised: 26 July 2017

Accepted: 29 July 2017

\section{*Correspondence:}

Dr. Sofia Andrade de Oliveira,

E-mail: sofia.gineco@gmail.com

Copyright: () the author(s), publisher and licensee Medip Academy. This is an open-access article distributed under the terms of the Creative Commons Attribution Non-Commercial License, which permits unrestricted non-commercial use, distribution, and reproduction in any medium, provided the original work is properly cited.

\begin{abstract}
Endometriosis is a chronic inflammatory disease, defined by the presence of endometrial tissue outside the uterine cavity. It causes symptoms such as dysmenorrhea, chronic pelvic pain, dyspareunia, infertility, with great loss of quality of life for the patient. The objective of the study was to compare, through a meta-analysis, GnRH analogues, which are considered clinical first line treatment for endometriosis, versus dienogest, a selective oral progestin in the treatment of endometriosis. A systematic review was conducted to select the studies. In total, 31 articles were found. Four studies met criteria, the following variables were analyzed: pelvic pain, dyspareunia and induration of the Pouch of Douglas after treatment and it was evaluated the presence of side effects during treatment: hot flushes, headache and BMD loss. There was no difference between the dienogest group and GnRH analogue group when it was evaluated maintenance of lower abdominal pain, dyspareunia, induration of the Pouch of Douglas after treatment and hot flushes during treatment. Besides those results, the dienogest group had a lower incidence of headache and less BMD loss. The treatment of endometriosis continues to be a challenge, even with new treatment options such as new drugs (dienogest) and surgical procedures. This meta-analysis provides evidence of the absence of dienogest inferiority compared with GnRH analogues with less BMD loss and less headache incidence.
\end{abstract}

Keywords: Clinical treatment, Dienogest, Endometriosis, Gonadotropin-releasing hormone

\section{INTRODUCTION}

Endometriosis is a chronic inflammatory disease and it is defined as the presence of functional endometrium-like tissue outside of the uterine cavity. It is an estrogen dependent disease and it regresses after the menopause. It is estimated that this disease affects $5 \%-15 \%$ of women in reproductive age. ${ }^{1}$ The main symptoms are dysmenorrhea, deep dyspareunia, chronic pelvic pain and infertility. ${ }^{2}$ If endometriosis involves the rectum or bladder, dyschezia or dysuria may be present and it can cause a severe impact on quality of life. ${ }^{3}$

As in all chronic inflammatory diseases, it is necessary a prolonged clinical therapy in endometriosis. The objective of the treatment is the suppression and control of endometriotic lesions. ${ }^{1}$ There is frequent recurrence of symptoms after interruption of treatment with conservative therapy. Gonadotrophin-releasing hormone 
analogues (GnRH-a), progestins or combined oral contraceptives (COCs) are the most frequently used hormonal treatment. ${ }^{3}$ Although effective, most of these options are associated with side-effects, which may affect compliance and preclude long-term use. ${ }^{3}$

GnRH-a, like buserelin, leuprolide acetate and triptorelin, are currently the most widely used medical therapies for endometriosis. $^{2}$ They decrease the production of gonadotropins and they suppress ovulation, so they induce a pharmacological menopause. ${ }^{1}$ Therefore, long term use of GnRH-a is associated with hypo-estrogenic side effects: irregular menstrual period, hot flushes, vaginal burning, decreased libido and decreased bone mineral density. ${ }^{4}$ Consequently, the use of GnRH-a is limited to a maximum of 6 months. ${ }^{2}$

Dienogest (DNG) is a fourth-generation selective progestin that exhibit high selectivity for binding to progesterone receptors. It has a potent oral progestational activity and little androgenic, estrogenic, glucocorticoid or mineralocorticoid activity and minimal impact on metabolic parameters. It reduces endometriotic lesions by creating a local progestogenic environment, suppressing the systemic estrogen level moderately. ${ }^{3}$

DNG has both anovulatory and antiproliferative effect. ${ }^{1}$ It suppresses the proliferation and the secretion of IL-8 from endometriotic stromal cells. DNG is frequently associated with irregular uterine bleeding, that is a common adverse effect of progestins, however the incidence of adverse effects caused by hypo-estrogenic state was not so expressive. ${ }^{2}$ This therapy may offer advantages in terms of safety and tolerability. ${ }^{3}$

The objective of this study is to compare, through a metaanalysis, the GnRH-a, that is considered the gold standard clinical treatment for endometriosis, with the DNG, a selective oral progestin, in the treatment of endometriosis.

\section{Evidence acquisition}

To report the results of this meta-analysis, we utilized the Preferred Reporting Items for Systematic Reviews and Meta-Analysis (PRISMA) statement. $^{5}$ This systematic review is registered in the PROSPERO database under CRD42016050501.

\section{Search question}

In order to determine the focus of the systematic review, we establish the clinical question considering five components: the population that we will study, the intervention and comparators, outcomes and study design of which we will get the data. ${ }^{6}$ Thus, our proposition for the systematic review was "to examine the efficacy of the DNG in the treatment of women with endometriosis compared to GnRH-a. We will use evidence from randomized controlled studies only."
Structured in the "PICOS" format: Population, Intervention, Comparator, Outcome, Study design; the question of the systematic review was to search the literature to answer. ${ }^{7}$ (Table 1).

Table 1: Selection criteria of included studies (PICOS).

\begin{tabular}{|c|c|c|}
\hline & Included & Excluded \\
\hline Population & $\begin{array}{l}\text { Women with } \\
\text { endometriosis } \\
\text { diagnosed }\end{array}$ & \\
\hline Intervention & $\begin{array}{l}\text { Dienogest as treatment } \\
\text { of endometriosis }\end{array}$ & \\
\hline Comparison & $\begin{array}{l}\text { GnRH-a as treatment } \\
\text { of endometriosis }\end{array}$ & \\
\hline \multirow{6}{*}{$\begin{array}{l}\text { Outcomes } \\
\text { (during } \\
\text { treatment) }\end{array}$} & Primary: & \\
\hline & Incidence of headache & \\
\hline & $\begin{array}{l}\text { Incidence of hot } \\
\text { flushes }\end{array}$ & \\
\hline & $\begin{array}{l}\text { Bone mineral density } \\
\text { loss }\end{array}$ & \\
\hline & Secondary: & \\
\hline & None & \\
\hline \multirow{6}{*}{$\begin{array}{l}\text { Outcomes } \\
\text { (after } \\
\text { treatment) }\end{array}$} & Primary: & \\
\hline & $\begin{array}{l}\text { Incidence of lower } \\
\text { abdominal pain }\end{array}$ & \\
\hline & $\begin{array}{l}\text { Incidence of } \\
\text { dyspareunia }\end{array}$ & \\
\hline & $\begin{array}{l}\text { Incidence of } \\
\text { induration of the } \\
\text { pouch of Douglas }\end{array}$ & \\
\hline & Secondary & \\
\hline & None & \\
\hline Study type & Randomized studies & $\begin{array}{l}\text { Systematic } \\
\text { reviews and } \\
\text { meta- } \\
\text { analysis, } \\
\text { quasi- } \\
\text { randomized, } \\
\text { non- } \\
\text { randomized, } \\
\text { retrospective } \\
\text { or case- } \\
\text { control } \\
\text { studies }\end{array}$ \\
\hline
\end{tabular}

- P: Women with endometriosis diagnosed

- I: Dienogest

- C: GnRH-a

- O: Efficacy

- S: Randomized Studies

\section{Eligibility criteria}

For an article to be selected for review, it should

- Include women with endometriosis diagnosed 
- Compare the efficacy of GnRH-a versus the GnRH-a in the treatment of endometriosis

- Be a prospective, controlled, randomized study

- To be published in a peer-reviewed journal. ${ }^{8}$

The study was excluded if

- It was published in the form of abstracts, letters to the editor and comments or "grey literature"

- It was with secondary outcomes (meta-analysis) or systematic reviews

- If there were any other drug involved in the comparison beyond dienogest and GnRH-a.

\section{Search strategy}

An electronic search was performed using the MEDLINE, PubMed in September 2016. We restricted the search to articles published in English. The search combined relevant terms and MeSH (Medical Subject Headings of the National Library of Medicine) descriptors related to "Buserelin" OR "Goserelin" OR "Leuprorelin" OR "Nafarelin" OR "Triptorelin" OR "Gonadotropin-Releasing Hormone" AND “dienogest".

\section{Studies selection}

The selection of publications was carried out by two researchers (SAO, BSM) and independently. Initially, reviewers evaluated the title and abstract of all found studies, by the search strategy. Then, all the items that did not provide sufficient information regarding the criteria for inclusion and non-inclusion in the title and summary were evaluated in full. It was included in the metaanalysis only studies that met the inclusion criteria and did not satisfy the criteria for non-inclusion.

\section{Data collection process}

Two researchers (SAO, BSM), independently, extracted data using a standardized form and, again, any discrepancies were resolved by consensus.

They were extracted and combined data from all included studies that reported outcomes related to procedures and patients. These authors assessed the eligibility and quality of the studies and subsequently extracted data from the articles. The standardized form included a lot of different information, such as the study title, authors, journal where it was published, year of publication, sample size, design and duration of the study, the demographics of participants, and type of procedure.

\section{Data and outcomes}

Six questions about comparing dienogest versus GnRH-a treatment were prepared for this article, as follows:

- What is the best medication in the treatment of endometriosis?

- Which medication is better to treat the dyspareunia caused by the endometriosis?

- Which medication is better to treat the induration of the pouch of Douglas caused by endometrioses?

- Which medication is better to treat the lower abdominal pain caused by endometriosis?

- Which medication is better in terms of causing fewer side effects like headache and hot flushes?

- Which medication is better in terms of causing less BMD loss?

No other variable was evaluated by more than one of the articles, that is why only these variables (dyspareunia, induration of the pouch of Douglas, lower abdominal pain, headache, hot flushes and BMD loss) were used for analysis. The variable genital bleeding or spotting was not included because the methodology and analysis criteria of the articles were different, preventing a metaanalytic review.

\section{Risk of bias assessment}

We followed the guidance suggested by the Cochrane Collaboration to assess the risk of bias from the included studies. ${ }^{9}$

We evaluated sequence generation, allocation concealment, blinding, and incomplete outcome data for each trial included in the review. A low risk of bias was considered when a judgment of "yes" for all domains was obtained, whereas a high risk of bias was considered when a judgment of "no" for one or more domains was obtained. The quality assessment of the included trials is shown in Table 2.

\section{Analysis}

To carry out the meta-analysis, it was used the Cochrane Collaboration's Review Manager software (RevMan 5.3; <http://tech.cochrane.org/revman>).

Table 2: Quality assessment of included trials.

\begin{tabular}{|lllll|}
\hline Study & Sequence generation & Allocation concealed & Blinding & Incomplete outcome data \\
\hline Harada $^{10}$ & Yes & Yes & Yes & Yes \\
\hline Cosson $^{11}$ & Yes & Yes & No & Yes \\
\hline Strowitzki $^{12}$ & Yes & Yes & No & Yes \\
\hline Takaesu $^{13}$ & Yes & Yes & No & Yes \\
\hline
\end{tabular}


The $\mathrm{Q}$ value of the statistical test was the Cochran Q (Chi $\wedge 2=4.00, \quad \mathrm{p}=0.14)$, indicating no evidence of heterogeneity between studies. From the $\mathrm{I}^{2}$ statistical of Higgins and Thompson the observed value was $\mathrm{I}^{2}=50 \%$, indicating moderate heterogeneity. Taking this into account, a fixed effect model through the MantelHaenszel method (M-H) was considered. ${ }^{14-17}$ A systematic literature search was performed to identify randomized studies comparing Dienogest against GnRHa in endometriosis. It was done, on 08.14.2016, a search of publications in PubMed using keywords including: "Buserelin" OR "Goserelin" OR "Leuprorelin" OR "Nafarelin" OR “Triptorelin" OR "GonadotropinReleasing Hormone" and "dienogest". In total, it was found 31 articles. All articles were read and the randomized articles about endometriosis were selected for the meta-analysis. There were, in total, 6 randomized articles however, two were excluded because one of them was about $\mathrm{GnRH}-\mathrm{a}$ and dienogest plus estradiol valerate and the other one was excluded because it has the same database of another more updated that was used for the meta-analysis. It was not found nonrandomized prospective articles about this comparison. As a result, four trials were qualified for inclusion in the metaanalysis. $^{10-13}$

\section{Description of the included studies}

Overall, the four included studies accounted for 753 patients (376 in dienogest group and 377 in the GnRH analogue group). We summarized and tabulated the extracted data from the included studies (Attachment 1). Two studies (Takaesu, 2016 and Cosson, 2002) administered the medications and followed the patients after laparoscopic surgery. The other studies (Harada, 2009 and Strowitzki, 2012) did not performed surgery during the period of investigation. Because there was divergence in the methodology of articles was chosen to separate the articles into two metanalysis: Takaesu, 2016 and Cosson, 2002; Harada, 2009 and Strowitzki, 2012.

\section{Evidence synthesis outcomes lower abdominal pain}

That evaluated the maintenance of lower abdominal pain after treatment. It was possible to analyze only the articles Harada et al., 2009 and Strowitzki et al., 2012, because among other two articles, just Cosson et al., 2002, studied this variable and we could not make the meta-analytic review with only one article. When comparing the two treatments, there was no statistically significant difference between the groups $(\mathrm{RR}=1.04 ; 95 \%$ CI: $0.92,1.18 ; \mathrm{I} 2=0 \% ; \mathrm{p}=0.52$ ), (Figure 1).

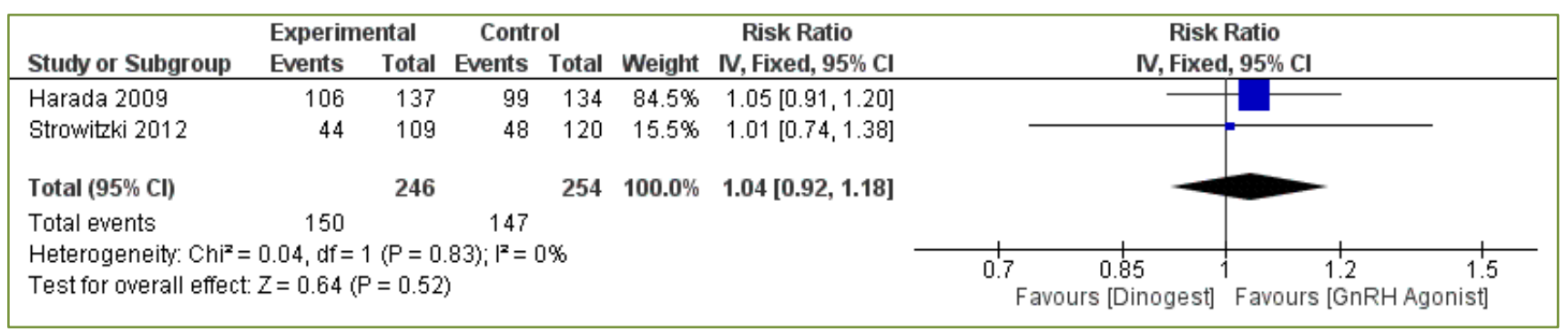

Figure 1: Forest-plot for the incidence of lower abdominal pain after treatment.

\section{Dyspareunia}

All studies (Cosson et al., 2002; Takaesu et al., 2016; Harada et al., 2009; Strowitzki et al., 2012) evaluated the maintenance of dyspareunia after treatment. When comparing the two treatments, there was no statistically significant difference between the groups. 1) Studies with laparoscopic surgery: $\mathrm{RR}=0.94 ; 95 \% \mathrm{CI}: 0.74,1.20$; $\mathrm{I} 2=5 \%$; $\mathrm{p}=0.63) ; 2$ ) Studies without surgery: $\mathrm{RR}=0.97$; 95\% CI: 0.77, 1.23; I2=0\%; $\mathrm{p}=0.83$ ); (Figure 2).

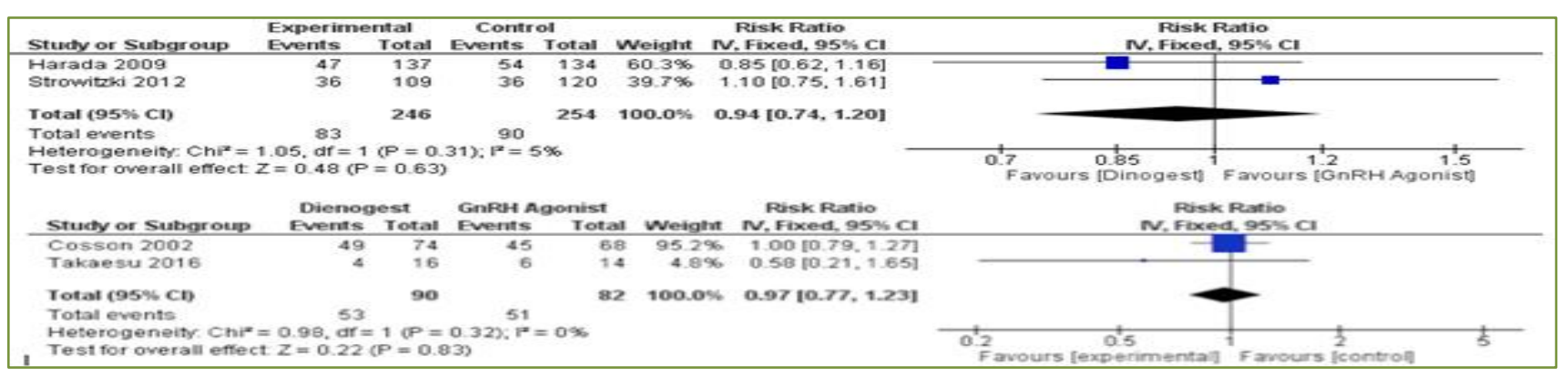

Figure 2: Forest-plot for the incidence of dyspareunia after treatment. 


\section{Induration of the pouch of douglas}

There were two studies (Harada et al., 2009; Strowitzki et al., 2012) that evaluated the maintenance of induration of the Pouch of Douglas after treatment.
When comparing the two treatments, there was no statistically significant difference between the groups $(\mathrm{RR}=0.96 ; 95 \% \mathrm{CI}: 0.86,1.08 ; \mathrm{I} 2=0 \% ; \mathrm{p}=0.52$ ), (Figure 3).

\begin{tabular}{|c|c|c|c|c|c|c|c|c|}
\hline \multirow[b]{2}{*}{ Study or Subgroup } & \multicolumn{2}{|c|}{ Experimental } & \multicolumn{2}{|c|}{ Control } & \multirow[b]{2}{*}{ Weight } & \multirow{2}{*}{$\begin{array}{c}\text { Risk Ratio } \\
\text { M-H, Fixed, } 95 \% \mathrm{Cl}\end{array}$} & \multirow{2}{*}{\multicolumn{2}{|c|}{$\begin{array}{c}\text { Risk Ratio } \\
\text { M-H, Fixed, } 95 \% \mathrm{Cl}\end{array}$}} \\
\hline & Events & Total & Events & Total & & & & \\
\hline Harada 2009 & 102 & 137 & 106 & 134 & $60.3 \%$ & $0.94[0.83,1.07]$ & 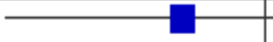 & \\
\hline Strowitzki 2012 & 67 & 109 & 74 & 120 & $39.7 \%$ & $1.00[0.81,1.22]$ & & \\
\hline Total $(95 \% \mathrm{Cl})$ & & 246 & & 254 & $100.0 \%$ & $0.96[0.86,1.08]$ & & \\
\hline Total events & 169 & & 180 & & & & & \\
\hline \multicolumn{7}{|c|}{$\begin{array}{l}\text { Heterogeneity: } \mathrm{Chi}^{2}=0.23, \mathrm{df}=1(P=0.63) ; \mathrm{I}^{2}=0 \% \\
\text { Test for overall effect: } Z=0.65(P=0.52)\end{array}$} & $\begin{array}{ll}0.85 & 0.9 \\
\text { Favours [Dienogest] }\end{array}$ & $\begin{array}{ccc}1.1 & 1.2 \\
\text { Favours [GnRH Agonist] }\end{array}$ \\
\hline
\end{tabular}

Figure 3: Forest-plot for the incidence of induration of the Pouch of Douglas after treatment.

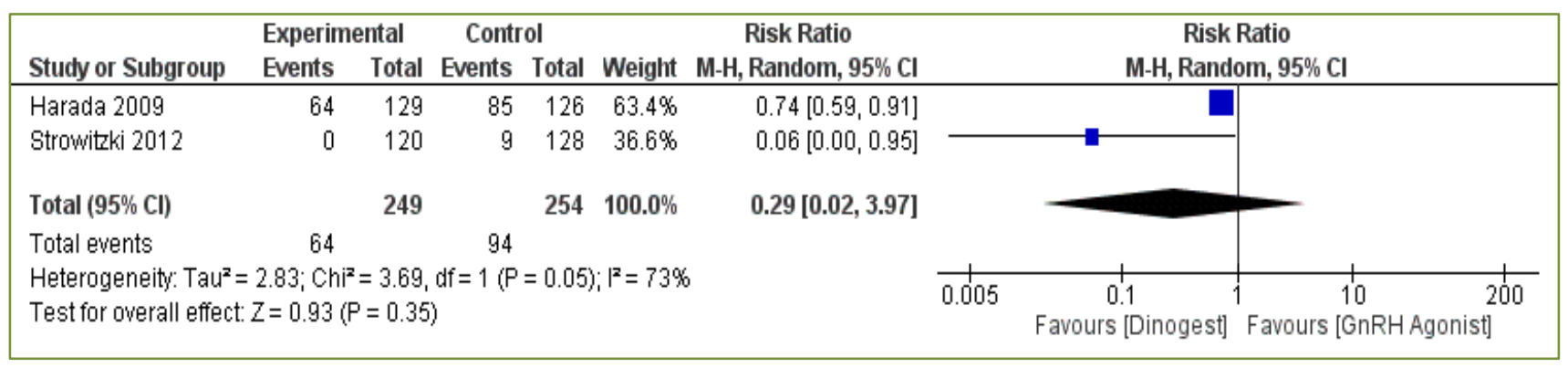

Figure 4: Forest-plot for the incidence of hot flushes during treatment.

\section{Hot flushes}

It evaluated the presence of hot flushes as side effect during treatment. It was possible to analyze only the articles Harada et al., 2009 and Strowitzki et al., 2012, because among other two articles, just Takaesu et al., 2016, studied this variable and we could not make the meta-analytic review with only one article.

When comparing the two treatments, there was no statistically significant difference between the groups $(\mathrm{RR}=0.29 ; 95 \% \mathrm{CI}: 0.02,3.97 ; \mathrm{I} 2=73 \% ; \mathrm{p}=0.35$ ), (Figure 4).

\section{Headache}

It evaluated the presence of headache as side effect during treatment. It was possible to analyze only the articles Harada et al., 2009 and Strowitzki et al., 2012, because among other two articles, just Takaesu et al., 2016 studied this variable and we could not make the meta-analytic review with only one article. When comparing the two treatments, there was a statistically significant difference between the groups $(\mathrm{RR}=0.70 ; 95 \%$ CI: $0.51,0.97 ; \mathrm{I} 2=0 \% ; \mathrm{p}=0.03$ ), (Figure 5). The GnRH-a group had a higher incidence of headache.

\begin{tabular}{|c|c|c|c|c|c|c|c|c|}
\hline \multirow[b]{2}{*}{ Study or Subgroup } & \multicolumn{2}{|c|}{ Experimental } & \multicolumn{2}{|c|}{ Control } & \multirow[b]{2}{*}{ Weight } & \multirow{2}{*}{$\begin{array}{c}\text { Risk Ratio } \\
\text { IV, Fixed, 95\% Cl }\end{array}$} & \multirow{2}{*}{\multicolumn{2}{|c|}{$\begin{array}{c}\text { Risk Ratio } \\
\text { IV, Fixed, 95\% Cl }\end{array}$}} \\
\hline & Events & Total & Events & Total & & & & \\
\hline Harada 2009 & 32 & 129 & 43 & 126 & $70.0 \%$ & $0.73[0.49,1.07]$ & 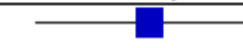 & $T$ \\
\hline Strowitzki 2012 & 15 & 120 & 25 & 128 & $30.0 \%$ & $0.64[0.35,1.15]$ & & \\
\hline Total $(95 \% \mathrm{Cl})$ & & 249 & & 254 & $100.0 \%$ & $0.70[0.51,0.97]$ & & \\
\hline Total events & 47 & & 68 & & & & & \\
\hline $\begin{array}{l}\text { Heterogeneity: } \text { Chi }^{2}= \\
\text { Test for overall effect }\end{array}$ & $\begin{array}{l}0.13, d f= \\
Z=2.17(\end{array}$ & $\begin{array}{l}(P=0 . \\
=0.03)\end{array}$ & $72) ; 1^{2}=0$ & & & & $\begin{array}{cc}1 & 1 \\
0.5 & 0.7 \\
\text { Favours } & \text { [Dinogest] }\end{array}$ & $\begin{array}{ccc}1 & 1.5 & 2 \\
\text { Favours [GnRH Agonist] }\end{array}$ \\
\hline
\end{tabular}

Figure 5: Forest-plot for the incidence of headache during treatment. 


\section{Bone mineral density}

There were two studies (Harada et al., 2009; Strowitzki et al., 2012) that evaluated the bone mineral density (BMD) after treatment. When comparing the two treatments, there was a statistically significant difference between the groups $(\mathrm{RR}=2.77$; 95\% CI: 0.16, 5.39; $\mathrm{I} 2=80 \%$; $\mathrm{p}=0.02)$. Treatment with dienogest resulted in less BMD loss than obtained with GnRH-a (Figure 6).

\begin{tabular}{|c|c|c|c|c|c|c|c|c|c|}
\hline \multirow[b]{2}{*}{ Study or Subgroup } & \multicolumn{2}{|c|}{ Experimental } & \multicolumn{3}{|c|}{ Control } & & \multirow{2}{*}{$\begin{array}{l}\text { Mean Difference } \\
\text { N, Random, } 95 \% \mathrm{Cl}\end{array}$} & \multirow{2}{*}{\multicolumn{2}{|c|}{$\begin{array}{l}\text { Mean Difference } \\
\text { N, Random, } 95 \% \mathrm{Cl}\end{array}$}} \\
\hline & Mean SD & Total & Mean & SD & Total & Weight & & & \\
\hline Harada 2009 & $\begin{array}{ll}-1 & 2.3\end{array}$ & 41 & -2.6 & 2.3 & 46 & $56.4 \%$ & $1.60[0.63,2.57]$ & & -1 \\
\hline Strowitki 2012 & 0.252 .77 & 21 & -4.04 & 4.84 & 29 & $43.6 \%$ & $4.29[2.17,6.41]$ & & \\
\hline Total (95\% Cl) & & 62 & & & & $100.0 \%$ & $2.77[0.16,5.39]$ & & \\
\hline $\begin{array}{l}\text { Heterogeneity. Taut } \\
\text { Test for overall effect }\end{array}$ & $\begin{array}{l}2.91 ; \mathrm{Chi}^{2}=5 . \\
Z=2.08(\mathrm{P}=0\end{array}$ & $\begin{array}{l}11, \mathrm{df}= \\
0.04)\end{array}$ & $=1(P=$ & $0.02 ; 1^{2}$ & $2^{2}=809$ & & & $\begin{array}{cc}-4 & -2 \\
\text { Favours [experimental) }\end{array}$ & $\begin{array}{ccc}0 & 1 & 4 \\
\text { Favours [control] }\end{array}$ \\
\hline
\end{tabular}

Fig 6. Forest-plot for the percentage change in the BMD.

\section{DISCUSSION}

In this study, we demonstrated evidences of the noninferiority of dienogest in comparison with gonadotropinreleasing hormone analogues at treatment of endometriosis. There was no difference between the dienogest group and GnRH-a group when it was evaluated maintenance of lower abdominal pain, dyspareunia, induration of the Pouch of Douglas after treatment and hot flushes during treatment. Besides those results, the dienogest group had a lower incidence of headache and less BMD loss.

In 1998, a study with rats was done to evaluate the activity of dienogest in endometrium tissue and it concluded that dienogest is a potent agent for endometriosis with a direct inhibitory action on the proliferation of ectopic endometrial tissue and that it normalizes the peritoneal environment, restores $\mathrm{NK}$ activity, and suppresses bone mineral loss, all actions which are clearly lacking in the case of danazol and buserelin. ${ }^{18}$

A multi-center, prospective, randomized study performed in Italy, evaluated the efficacy of dienogest plus estradiol valerate and gonadotrophin-releasing hormone analogue in reducing recurrence of pain in patients with chronic pelvic pain due to endometriosis after laparoscopic surgery. At results, visual analogue scale (VAS) data did not show significant differences in any of the follow-up visits between the two groups $(\mathrm{p}=0.417)$. At the 9-month follow up, a questionnaire to investigate quality of life was administered, and its results showed a considerable increase of scores for all women compared with before surgery, demonstrating an improvement in the quality of life and an equal health-related satisfaction with both treatments. $^{3}$ Other study has shown that dienogest $2 \mathrm{mg} /$ day is an effective therapy for endometriosis, superior to placebo. ${ }^{19}$ Petraglia et al made a multicenter, randomized study performed in Germany, Italy and Ukraine to evaluate efficacy and safety of dienogest as a long-term treatment in endometriosis, with follow-up after treatment discontinuation. ${ }^{19}$ It was an open-label extension study for up to 53 weeks after a 12-week placebo-controlled study of dienogest, at $2 \mathrm{mg}$ once daily. Thereafter a patient subgroup was evaluated in a 24-week follow-up after treatment discontinuation. The mean (VAS) score at baseline of the extension study was 34.08 $\mathrm{mm}$ (standard deviation (SD) $\pm 21.60 \mathrm{~mm}$ ) in the total population. The mean VAS score progressively and significantly decreased to $11.52( \pm 11.26) \mathrm{mm}$ at the end of the extension study in the total population. The mean VAS score was significantly reduced by $43.2( \pm 21.7) \mathrm{mm}$ over the total treatment period of 65 weeks (i.e., the placebo-controlled plus extension study; $\mathrm{P}<0.001)$. During the treatment-free follow-up, the mean VAS score increased slightly from the end of the extension study to $16.29( \pm 14.08) \mathrm{mm}$ at week 12 and $14.56( \pm 9.55) \mathrm{mm}$ at week 24.

Strowitzki et al made the evaluation of the reduction in mean VAS over 24 weeks of treatment. ${ }^{12}$ The absolute reduction in mean VAS was $47.5 \pm 28.8 \mathrm{~mm}$ with dienogest (DNG) and $46.0 \pm 24.8 \mathrm{~mm}$ with leuprolide acetate (LA), representing a treatment difference of 1.5 $\mathrm{mm}$ in favor of dienogest. It was concluded that dienogest showed non-inferiority to leuprolide acetate for relief of endometriosis-related pelvic pain. According to Biberoglu and Behrman score, total pelvic symptoms at screening were severe in $21 \%$ and $10 \%$ of women in the DNG and LA groups, respectively, and were moderate in approximately another two-thirds (DNG, 59\%; LA, $61 \%) .{ }^{20}$ Following 24 weeks of treatment, no women had 
severe symptoms and only 5\% had moderate symptoms in both groups. About dysmenorrhea, the proportion of women free from this symptom at study end was $82 \%$ in the DNG group and $90 \%$ in the LA group. No women in either group reported severe dysmenorrhea at study end. About physical and mental health, mean Short-Form-36 Health Survey (SF-36) scores for total physical and mental health at baseline were 42.4 and 41.6, respectively, in the DNG group and 43.9 and 44.9, respectively, in the LA group. At the end of treatment, quality of life showed more pronounced absolute improvements in the DNG group than in the LA group, including both the physical health (DNG, 10.2 points; LA, 7.0 points) and the mental health (DNG, 3.3 points; LA, 1.9 points) summary scale scores. Compared with LA, DNG was also associated with greater relative improvements in specific SF-36 scale categories. In particular, DNG produced greater improvements in the categories "physical functioning" (DNG, 18.0\%; LA, $6.8 \%$ ), "role-physical" (DNG, 75.7\%; LA, 33.6\%), "vitality" (DNG, 28.3\%; LA, 12.3\%), and "social functioning" (DNG, 21.4\%; LA, 8.7\%). Laboratory safety parameters showed clinically relevant changes only at the substantial decreases in serum estradiol levels associated with LA, whereas DNG was associated with relatively stable levels.

Other hypoestrogenic effects such as: vaginal dryness, decreased libido and sleep disorder, were also reported more frequently by women treated with GnRH analogs than those treated with dienogest. ${ }^{12}$

In the literature, the average duration of treatment with GnRH-a is 6 months. The current trend is to use them for no more than 3 to 4 months, as they have harmful effects on bone metabolism. This side effect causes a limitation on the use of GnRH-a to treat this chronic disease leading the patient to multiple surgery indications to pain control. ${ }^{11}$ Dienogest is a drug that can change this situation because the BMD loss with dienogest is more discreet.

\section{CONCLUSION}

The dienogest group had a lower incidence of headache (RR=0.70; 95\% CI: 0.51, 0.97; $\mathrm{I}^{2}=0 \% ; \mathrm{p}=0.03$ ) and less BMD loss (RR=2.77; 95\% CI: 0.16, 5.39; $\mathrm{I}^{2}=80 \%$; $\mathrm{p}=0.02)$. There was no statistically significant difference about the maintenance of lower abdominal pain and dyspareunia (with laparoscopy or not): $(\mathrm{RR}=1.04 ; 95 \%$ CI: $\left.0.92,1.18 ; \mathrm{I}^{2}=0 \% ; \mathrm{p}=0.52\right),(\mathrm{RR}=0.94 ; 95 \% \mathrm{CI}: 0.74$, $\left.1.20 ; \mathrm{I}^{2}=5 \% ; \mathrm{p}=0.63\right)$ and $(\mathrm{RR}=0.97 ; 95 \% \mathrm{CI}: 0.77,1.23$; $\left.\mathrm{I}^{2}=0 \% ; \quad \mathrm{p}=0.83\right)$, respectively. There was also no statistically significant difference about the presence of hot flushes as side effect during treatments $(\mathrm{RR}=0.29$; 95\% CI: 0.02, 3.97; $\mathrm{I}^{2}=73 \% ; \mathrm{p}=0.35$ ).

Funding: No funding sources Conflict of interest: None declared
Ethical approval: The study was approved by the Institutional Ethics Committee

\section{REFERENCES}

1. Andres MP, Lopes LA, Baracat EC, Podgaec S. Dienogest in the treatment of endometriosis: Systematic review. Arch Gynecol Obstet. 2015;292:523-9.

2. Kitawaki J, Kusuki I, Yamanaka K, Suganuma I. Maintenance therapy with Dienogest following gonadotropin-releasing hormone agonist treatment for endometriosis-associated pelvic pain. Eur J Obstet Gynecol Reprod Biol. 2011;157:212-6.

3. Granese R, Perino A, Calagna G, Saitta S, De Franciscis $\mathrm{P}$, Colacurci $\mathrm{N}$ et al. Gonadotrophinreleasing hormone analogue or dienogest plus estradiol valerate to prevent pain recurrence after laparoscopic surgery for endometriosis: a multicenter randomized trial. Acta Obstet Gynecol Scand. 2015;94(6):637-45.

4. Takenaka, M. Exploratory study of pre-surgical medications with Dienogest or Leuprorelin in laparoscopic cystectomy of endometrial cysts. J Obstet Gynaecol Res. 2015:41(8);1234-9.

5. Moher D, Liberati A, Tetzlaff J, Altman DG. Preferred reporting items for systematic reviews and meta-analyses: the PRISMA statement. BMJ. 2009;339:332-9.

6. Methley AM, Campbell S, Chew-Graham C, McNally R, Cheraghi-Sohi S. PICO, PICOS and SPIDER: a comparison study of specificity and sensitivity in three search tools for qualitative systematic reviews. BMC Health Serv Res. 2014; 14:579.

7. Howick J. Oxford Centre for Evidence-based Medicine - Levels of Evidence; 2009. Available in: http://www.cebm.net/oxford-centre-evidence-basedmedicine-levels-evidence-march-2009/.

8. Higgins JPT, Green S. Cochrane Handbook for Systematic Reviews of Interventions Version 5.1.0. The Cochrane Collaboration, 2011. Available in: www.cochrane-handbook.org.

9. Higgins JPT, Thompson SG, Deeks JJ, Altman DJ. Measuring inconsistency in meta-analyses. BMJ. 2003;327(7414):557-60.

10. Harada T, Momoeda M, Taketani Y, Aso T, Fukunaga $\mathrm{S}$, Hagino $\mathrm{H}$, et al. Dienogest is as effective as intranasal buserelin acetate for the relief of pain symptoms associated with endometriosis - a randomized, double-blind, multicenter, controlled trial. Fertil Steril. 2009;91(3):675-81.

11. Cosson M, Querleu D, Donnez J, Madelenat J, Koninckx P, Audebert A, et al. Dienogest is as effective as triptorelin in the treatment of endometriosis after laparoscopic surgery: results of a prospective, multicenter, randomized study. Fertil Steril. 2002;77(4):684-92.

12. Strowitzki T, Marr J, Gerlinger C, Faustmann T, Seitz C. Detailed analysis of a randomized, 
multicenter, comparative trial of dienogest versus leuprolide acetate in endometriosis. Int $\mathrm{J}$ Gynecol Obstet. 2012;117:228-33.

13. Takaesu Y, Nishi H, Kojima J, Sasaki T, Nagamitsu $\mathrm{Y}$, Kato R, et al. Dienogest compared with gonadotropin-releasing hormone agonist after conservative surgery for endometriosis $\mathrm{J}$ Obstet Gynaecol Res. 2016;42(9):1152-8.

14. Borenstein M, Hedges LV, Higgins J, Rothstein HR. Introduction to Meta-Analysis, 1st Edition. Chichester, UK: John Wiley and Sons; 2009:391403.

15. Der Simonian R, Laird N. Meta-analysis in clinical trials. Controlled Clinical Trials. 1986:7(3);177-88.

16. Higgins JP, Thompson SG. Quantifying heterogeneity in a meta-analysis. Statistics in Medic. 2002:21(11);1539-58.

17. Sutton AJ, Abrams KR, Jones DR, Jones DR, Sheldon TA, Song F. Methods for meta-analysis in medical research. 1st Edition. Leicester, UK: John Wiley and Sons; 2000:37-56.
18. Katsuki Y, Takano Y, Futamura Y, Shibutani Y, Aoki D, Udagawa Y, et al. Effects of dienogest, a synthetic steroid, on experimental endometriosis in rats. Eur J Endocrinol. 1998;138:216-26.

19. Petraglia F, Hornung D, Seitz D, Faustmann T, Gerlinger C, Luisi S, et al. Reduced pelvic pain in women with endometriosis: efficacy of long-term Dienogest treatment. Arch Gynecol Obstet. 2012;285(1):167-73.

20. Biberoglu KO, Behrman SJ. Dosage aspects of danazol therapy in endometriosis: short term and long term effectiveness. Am J Obstet Gynecol. 1981;139:645.

Cite this article as: de Oliveira SA, Melo BS, Pereira MF. Dienogest versus gonadotropin-releasing hormone analogue for the clinical treatment of endometriosis: a systematic review and metaanalysis. Int J Reprod Contracept Obstet Gynecol 2017;6:3712-20. 


\section{Annexure}

\section{Annexure-I}

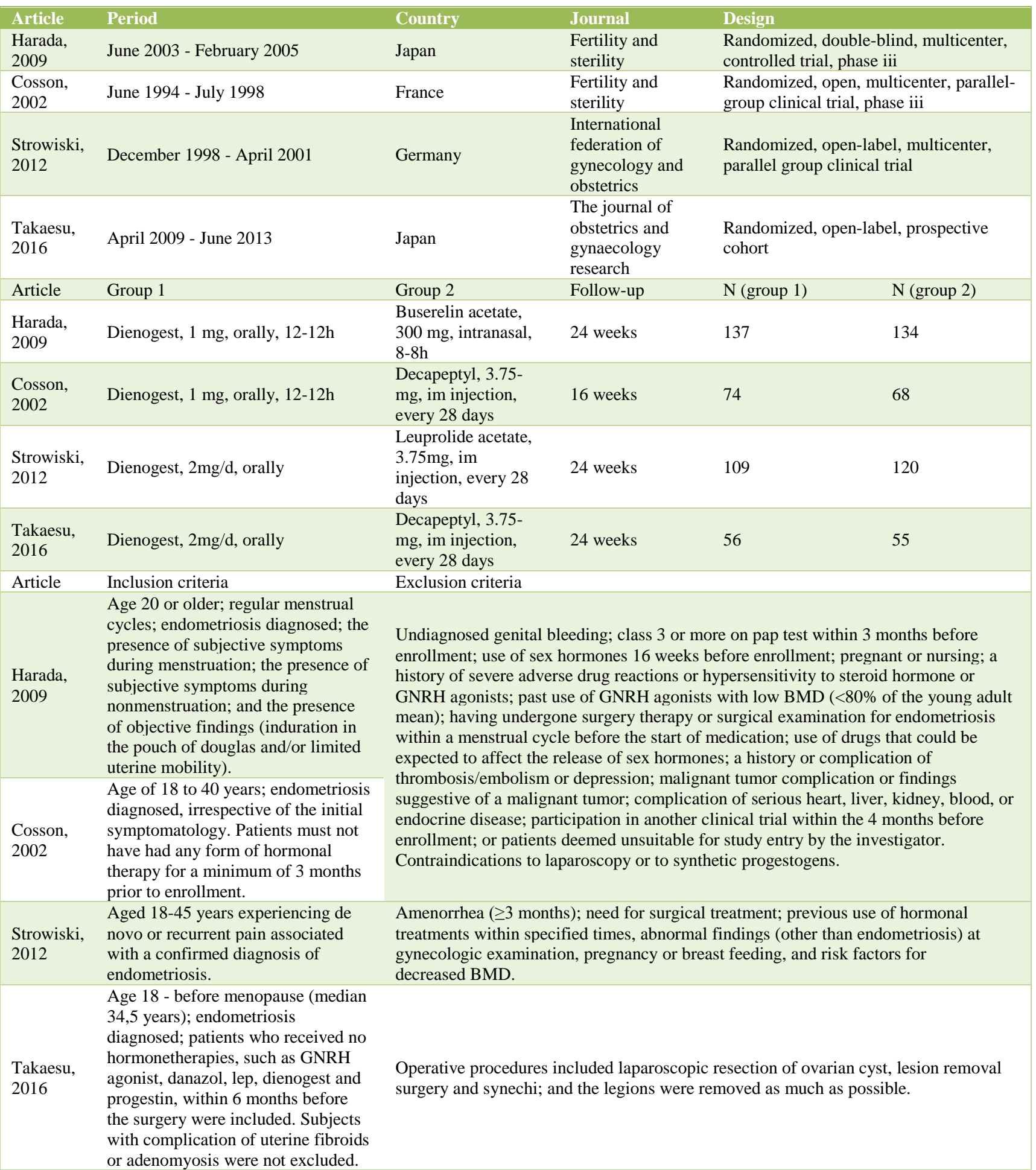

